\title{
Indirect Control of Corporations: Analysis and Simulations
}

\author{
Izabella Stach*
}

\begin{abstract}
This paper is devoted to the concept of indirect control in corporate shareholding networks. This topic is important in financial economics. Since shareholding size does not actually reflect an investor's power-control in corporate shareholding networks, diverse approaches to measuring the control-power of investors has been proposed. We focus in particular on a game-theoretical approach; specifically the model of Denti and Prati (2001) and its implementation to control sharing analysis and simulation in shareholding networks thanks to the computer program „Control Sharing Simulation”.
\end{abstract}

Keywords: corporate shareholding analysis, cooperative game theory, direct and indirect control, financial and economic modeling, power indices

Mathematics Subject Classification: 91A06, 91A12, 91B12

Submitted: March 06, 2017

Revised: May 13, 2017

\section{INTRODUCTION}

This paper is an improvement of a previous research document presented at the ICIL 2016 conference (Kołodziej and Stach, 2016). However, we analyze more literature here and present additional applications of the considered model.

This paper focuses on financial and economic modeling and, in particular, on the indirect control of corporations. This topic is important in financial economics, but it is not easily modeled. In corporate shareholding structures, determining who has power within a stock corporate company might be a very complex problem. The presence of cross-shareholdings (i.e., pairs of companies that exchange share holdings) and loops (i.e., for example, when Company A owns a stake in B, B owns a stake in $\mathrm{C}$, and $\mathrm{C}$ in $\mathrm{A}$ ) in a cross-shareholding structure allow an investment to control a company even with a small stake. The large and complex shareholding networks (i.e., with the presence of cross-shareholdings and loops) could be non-transparent. Then, analyzing their structures, it is sometimes possible to find that a small number of

* AGH University of Science and Technology, Faculty of Management, Krakow, Poland, e-mail: istach@zarz.agh.edu.pl 
tightly connected large companies control a significant part of the rest of the companies; see, e.g., (Krause et al., 2013; Vitali et al., 2011). Therefore, it is important to know the coalitions of firms that may exert control over a specific company or minimal coalitions (in size) that can control all companies in a closed shareholding network. Moreover, the size of the shares held in the company does not actually reflect an investor's power-control. Of course, the control/power that an investor can have over a certain firm is related to the percentage of shares that he/she owns, but it also depends on other factors. Specifically, a shareholder can have significantly more or less corporate control/power than the percentage of shareholding rights can reflect. In (Bajuri et al., 2014), an example of a company with three shareholders is given that reflects this problem. Here, we give a similar example; specifically, if the distribution of voting rights in a company among Shareholders 1, 2, and 3 is $60 \%, 25 \%$, and $15 \%$, respectively (see Fig. 1), then taking into account only shareholding size, it would appear that the degree of control/power for the each of the three investors is in proportion to the percentage of their voting rights. But in practice, the second and third shareholders are powerless under a simple-majority-rule voting system. The first shareholder is, of course, a "dictator" if the voting system does not require a greater than $60 \%$ majority of voting rights in making the important decisions. In other words, Shareholder 1 controls all outcomes of the corporate decisions. Thus, shareholding size does not reflect the actual power distribution in the shareholding structures. In (1954), Shapley and Shubik identified a successful implementation of power indices - cooperative game theory instruments - to measure the control/power in corporate networks; see also (Stach, 2011).

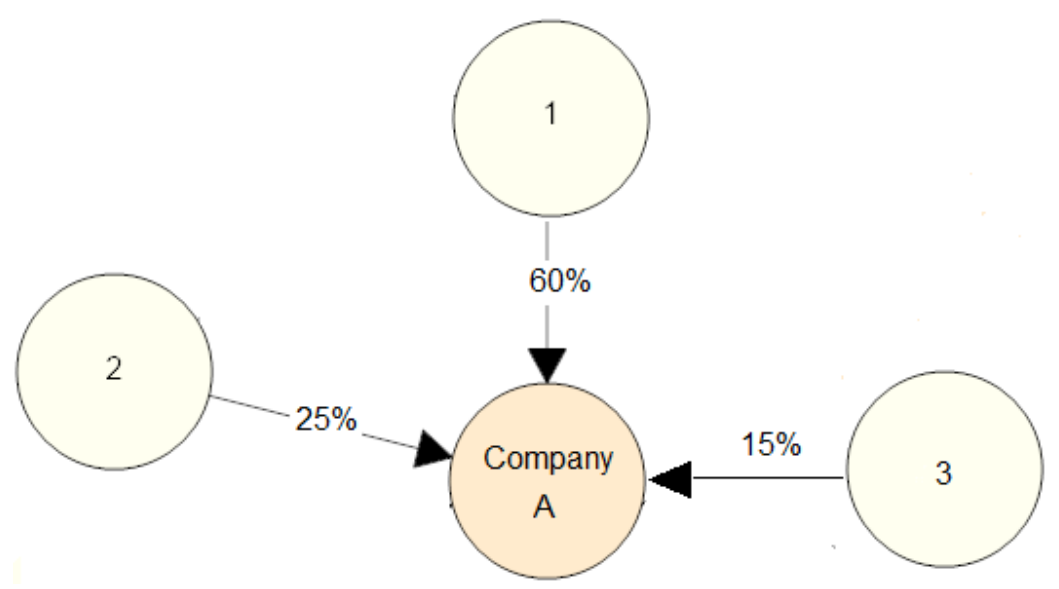

Fig. 1. Shareholding structure of Company A

Also in the automotive industry, the ownership networks are rather complicated and not at all transparent; see, for example, "Automotive industry," section "Company Relationships" in Wikipedia (https://en.wikipedia.org/wiki/Automotive। _industry, retrieved January 2017). In order to give an idea of how complicated 
the global shareholding structure of the automotive industry may be, we quote only a small fragment about the Ford Motor Company ownership relationships below:

(... ) Ford Motor Company holds a 3\% stake in Mazda, a 49\% share in Jiangling Motors. Ford and Navistar International have a 50-50 joint venture called Blue Diamond Truck. Ford and Sollers JSC have a 50-50 joint venture called Ford Sollers. Both Ford and Koç Holding own a $41 \%$ stake in Ford Otosan. Ford and Lio Ho Group have a joint venture called Ford Lio Ho, Ford owns 70\% and Lio Ho Group owns 30\% (...).

In the context of game theory, various approaches were proposed to model the corporate shareholding relationships and measure the indirect power of the firms involved in corporate shareholding networks. One rather pioneering one was the approach introduced by Gambarelli and Owen in (1994). Then in (1999), Turnovec proposed a way of determining the direct and indirect property distribution and the degree of transparency of an ownership structure. Since then, numerous other approaches have been proposed; for example, a reader can find a good and broad literature review of the most relevant references in this topic in (Crama and Leruth, 2007, 2013; Karos and Peters, 2015; Bertini et al., 2016).

Many game theoretical studies on indirect control in corporate networks recognized the importance of the voting power index. Mostly, the Shapley-Shubik and Banzhaf indices or their modifications have been applied to measure direct and indirect power/control [see, for example, (Hu and Shapley, 2003a, 2003b; Crama and Leruth, 2007, 2013; Karos and Peters, 2015); for the Banzhaf index, see (Banzhaf, 1965; Penrose, 1946, 1952); for Shapley-Shubik, see (Shapley and Shubik, 1954)]. However, there are some approaches that have used other indices. For example, Braham and Steffen in (2003) and Van der Brink and Steffen in (2008) considered the application of the Straffin index (Straffin, 1977, 1988, 1994) to measure positional power in a hierarchy of network structures. In (2013), Bajuri et al. sought to explore the potential of the Straffin index (also called "the partial homogeneity index" or "modified Shapley-Shubik index" by some researchers) as a viable control analysis technique from the corporate network perspective. In (2016), Mercik and Łobos proposed an approach to measure indirect control by a modification of the Johnston index (Johnston, 1978). And in (2015), Karos and Peters proposed a large class of indices that could satisfy four axioms and measure the power of the players in a shareholding network.

This paper concentrates on the model of Denti and Prati (2001) in particular. Denti and Prati, in $(2001,2004)$ and also Gambarelli and Owen in (1994) focused on determining the winning coalitions of firms in a controlling structure. The purpose of this paper is the implementation of the Denti and Prati approach to a power/controlsharing analysis in a real-world shareholding structure and to provide a few simulations thanks to the computer program "Control Sharing Simulation", elaborated by Kołodziej (2011) within in scope of his master's thesis.

As mentioned above, game-theoretical approaches use power indices in order to measure control in corporate networks. In such approaches, shareholders are interpreted as players in a simple game (particularly in a weighted majority game). Hereafter, we provide some game-theoretical preliminary notation and definitions [the same as those in (Kołodziej and Stach, 2016)] necessary to better understand the model presented in Section 3. 
Recall that a game is a set of rules describing strategic decision-making. In cooperative games, players can come together in order to obtain common advantages; thus, in cooperative games, binding agreements are possible before the start of the game. Let $N=\{1,2, \ldots, n\}$ be a finite set of players. Any subset $S$ of $N$ is called a coalition. The set of all coalitions is denoted by $2^{N}$. Formally, a cooperative game consists of two elements: (i) a set of players $N$; and (ii) the real-valued function $v: 2^{N} \rightarrow R$, called the characteristic function of the game, that associates with every coalition $S \subseteq N$, a number $v(S)$ called the worth of coalition $S$ in game $v$, and satisfies the following condition: $v(\emptyset)=0$. A simple game $v$ on $N$ is the game in which $v$ takes values from set $\{0,1\}$ and fulfils condition $v(T) \leqslant v(S)$ whenever $T \subseteq S$. Coalition $S$ is called winning if $v(S)=1$, and losing otherwise (i.e., if $v(S)=0$ ). By $W(v)$ (or just $W$ ), we denote the collection of all winning coalitions in game $v$. Player $i$ is critical in winning coalition $S$ if $S$ is winning with $i$ and losing without $i$. A minimal winning coalition is a winning coalition with all players who are critical. By $W^{m}(v)$ (or simply $W^{m}$ ), we denote a set of all minimal winning coalitions in $v$. Either $W$ or $W^{m}$ determines the game. A weighted majority game is a simple game in which weight $w_{i}$ (for instance, the percentage of voting rights) is assigned to each player $i$, and a coalition is winning when the sum of the weights of each coalition member is superior to a majority quota $q$ (for instance, $50 \%$ of the simple majority rule). Formally, in a weighted majority game, $S$ is winning if $w(S)=\sum_{i \in S} w_{i}>q$. A power index for simple games is a mapping $f$ that assigns vector $f(v)=\left(f_{1}(v), f_{2}(v), \ldots, f_{n}(v)\right)$ to any simple game $v$ with $n$ players, where real number $f_{i}(v)$ is the power of player $i$ in game $v$. In relation to corporate shareholding structures, we can quote Crama and Leruth (2007) that "power indices are expected to reflect the relative capacity of each shareholder (be it a firm or an individual) to impose its will to a target company, measured either by its ability to form coalitions with other shareholders to win a vote, or by its ability to change the final outcome of a vote by swinging its own vote". For some comparisons of power indices, see (Bertini et al., 2013; Bertini and Stach, 2015; Stach, 2016), for example.

This paper is organized as follows. In Section 2, we present some examples of corporate shareholding networks. Section 3 presents the Denti and Prati approach. Section 4 is devoted to the computer program "Control Sharing Simulation". In Section 5, some simulations are provided that apply the Denti and Prati approach to the examples described in Section 2. Finally, Section 6 concludes with some observations.

\section{ILLUSTRATIVE EXAMPLES OF CORPORATE NETWORKS}

Each complex shareholding structure may be represented in two compact ways: by a directed graph (e.g., Fig. 2) or by an $n \times n$ matrix (e.g., Tab. 1) such that the value at place $(i, j)$ represents the percentage of stocks of Firm $j$ owned by Firm $i$. Figures 3 and 4 show the shareholding networks with cycles in the graphs.

Figure 2 presents the simplified organization chart of the Porsche-Volkswagen corporate structure (from 2008 to 2013) considered in (Karos and Peters, 2015). The players are Porsche Family (1), Qatar (2), Lower Saxony (3), Porsche SE (4), Volkswagen AG (5), Porsche AG (6), and Others (7). Let us consider this case with 
majority quota $\mathrm{q}=80 \%$. In this case, we have seven players, where four of which $(1,2$, $3,7)$ are investors and three $(4,5,6)$ are stock companies.

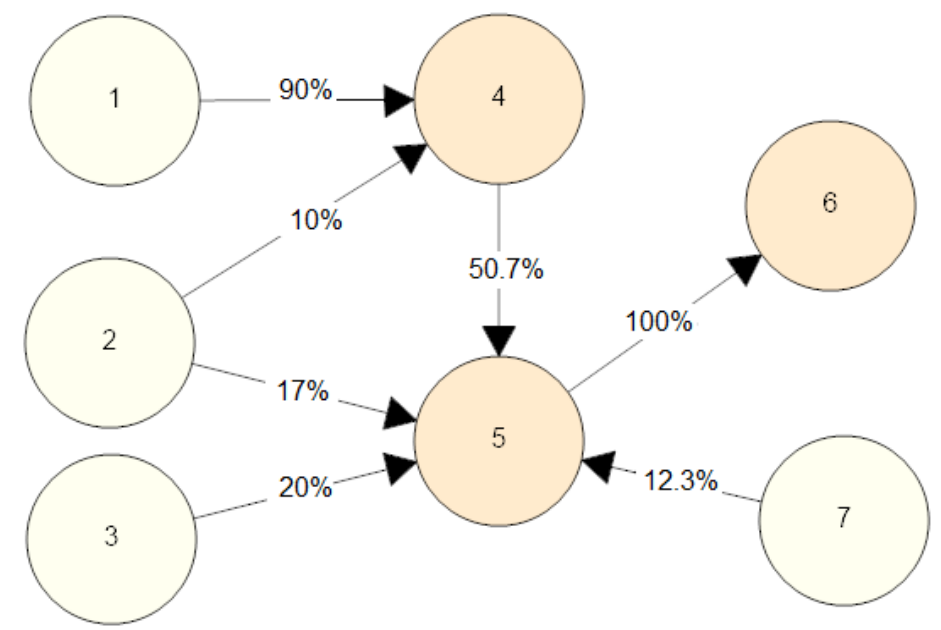

Fig. 2. Shareholding structure of Porsche-Volkswagen case

We will use the Porsche-Volkswagen case to provide some analyses and simulations, taking into account both the Denti and Prati approach and computer program "Control Sharing Simulation" (see Section 5).

Figure 3 presents an example of a corporate cyclic network. This example was considered in (Mercik and Łobos, 2016) and refers to the Speiser and Baker case. In this network, there are six players; three of which are investors. Specifically, these are the following players: Medallion (1), Speiser (2), HealthMed (3), HealthChem (4), Baker (5), and Others (6). Firms: 2, 5, and 6 are investors. For this case, we consider a simple majority quota of $q=50 \%$.

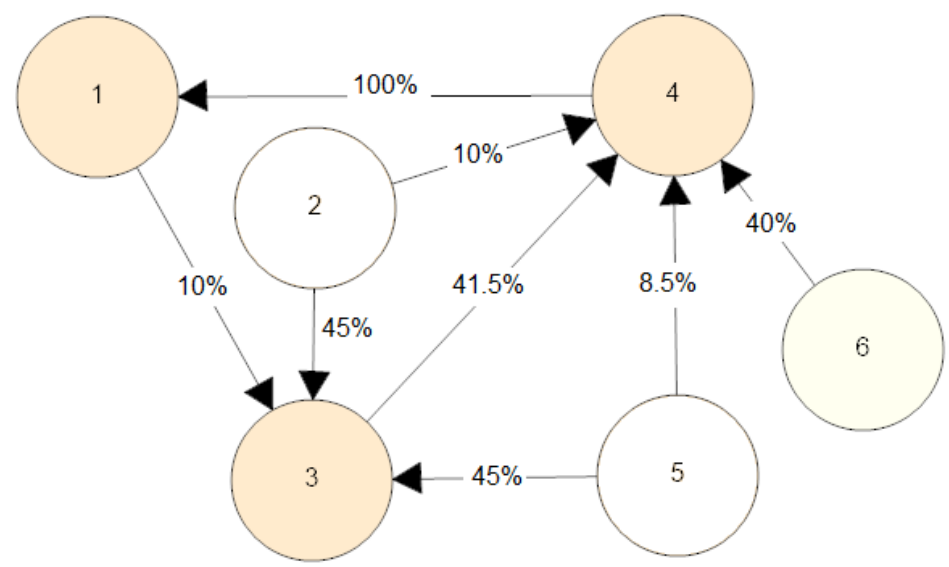

Fig. 3. Shareholding structure of Speiser-Baker case 
Figure 4 presents an example of a theoretical corporate shareholding network with eight investors (Firms 6, 7, 8, 9, 10, 11, 12, 13), five stock companies (Firms 1, 2, $3,4,5)$, and the presence of a cross ownership of stock and cycles. More precisely, in the considered shareholding structure, we have two loops and a cross-shareholding. Firm 2 owns $30 \%$ of the stock of Firm 3, Firm 3 owns $10 \%$ of the stock of Firm 5, and (on the other hand) Firm 5 owns $25 \%$ of the stock of Firm 2. Similarly, Firms 1, 2, and 4 form a loop. That is to say, Firm 1 has $3 \%$ of the stock of Firm 4, which owns $5 \%$ of the stock of Firm 2, and finally Firm 2 (with $35 \%$ of the stock of Firm 1) closes the circle. Then, Companies 1 and 4 (holding minority stakes in each other) form a cross-shareholding. The corporate structure given in Figure 4 is more complex than those presented in Figures 2 and 3. We will consider this example in Section 5 with a majority quota of $q=50 \%$ (simple majority).

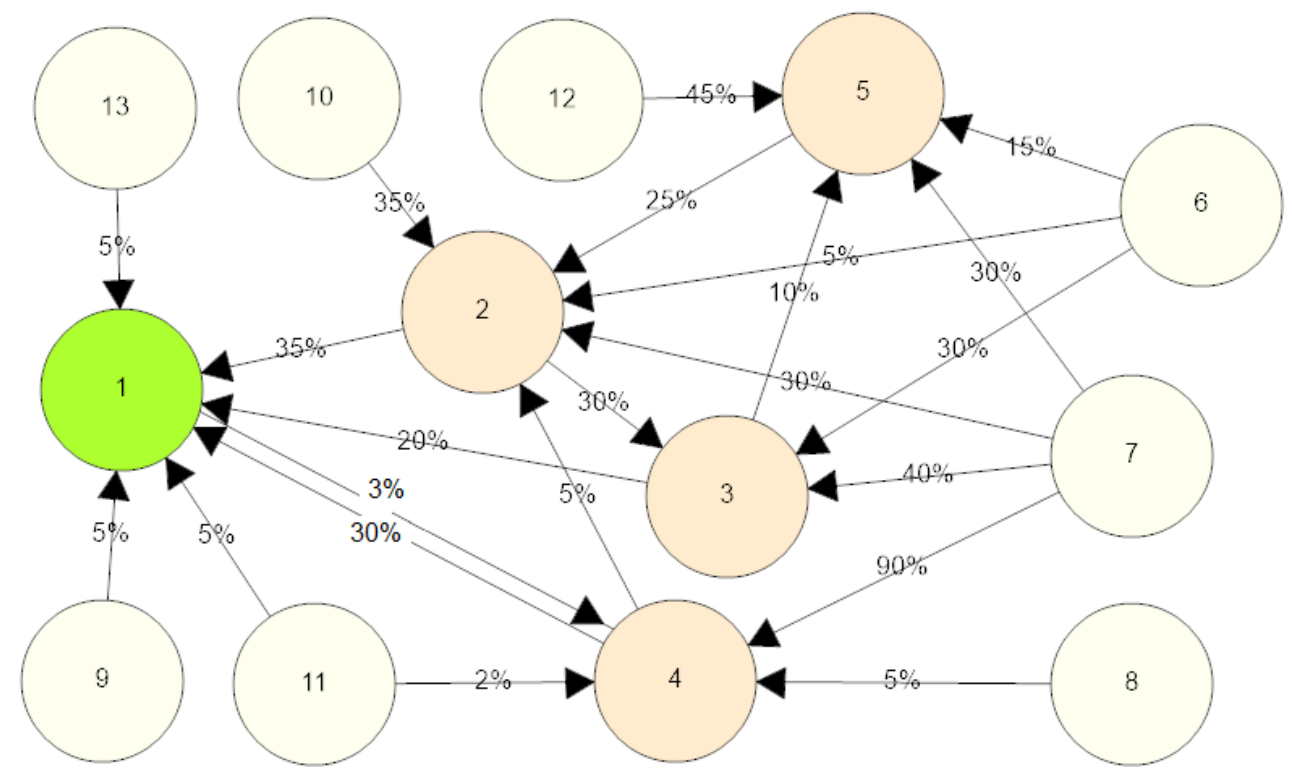

Fig. 4. A theoretical shareholding structure

\section{DENTI AND PRATI METHOD}

In (2001), Denti and Prati proposed an algorithm to find all of the winning coalitions in the corporate network of a given firm. They assumed that the number of direct and indirect shareholders is finite. Giving the set of all direct and indirect shareholders of a firm, the proposed algorithm is able to discover whether coalition $S$ is winning or not in any so-called formal game system (collection of weighted majority games). Denti and Prati do not limit the alliances able to achieve control of the target company solely to coalitions of only investors, like in the models of Gambarelli and Owen (1994) and Crama and Leruth $(2007,2013)$, for example. Here, the winning coalitions can be composed of both investors and stock companies. 
Let there be given a corporate shareholding network with $n$ firms. Let us assume that we would like to check if a certain coalition $S$ is able to control Firm $K$ in the considered network. The Denti and Prati algorithm can be briefly described as follows: in Step 0, coalition $S$ of the firms is represented by means of the $n$-dimensional vector of real numbers $Z_{0}=\left(z_{1}, \ldots, z_{n}\right)$ such that, for all $j=1,2, \ldots, n z_{j}=1$ if $z_{j} \in S$ and $z_{j}=0$ otherwise. In Step 1 , direct control is taken into account. More precisely, starting from vector $Z_{0}$, vector $Z_{1}$ is constructed replacing $z_{j}=0$ with $z_{j}=1$ if firm $j$ is directly controlled by $S$. In the next steps $i+1(i \geqslant 1)$, the indirect control is taken in account. Specifically, the algorithm proceeds by induction and modifies vector $Z_{i}$, putting 1 in place of $j$ if Firm $j$ is indirectly controlled by $S$ with the help of all of the firms (directly or indirectly controlled by $S$ ) selected in the previous steps. Since, by definition, the sequence of vectors $Z_{i}$ is non-decreasing and the number of firms is finite, the induction process reaches the end; i.e., $Z_{k+1}=Z_{k}$ for a certain index $k$ where $n>k \geqslant 0$. As a result, Firm $K$ is controlled by $S$ if vector $Z_{k}$ has " 1 " in the place representing Firm $K$; otherwise, $K$ is not controllable by $S$.

Let us see how this algorithm works through an example. Consider, for instance, the corporate shareholding structure shown in Figure 4. In this example, we have $n=13$ firms. Suppose we want to study coalition $S=\{7,10\}$. For this purpose, we can first look for the firms that are controlled directly by $S$ (i.e., those firms connected by just one arc to each firm in $S$ ) and then look for the firms that are controlled by $S$ indirectly (i.e., with the help of the firms selected in the previous step). In the first step (direct control), $S$ controls Firms 2 and 4 ; but in the second step, $S$ controls Firms 1 and 3 as well (with the help of Firms 2 and 4). However, even with the help of the other controlled firms, the coalition can control nothing else.

Thus,

$$
\begin{aligned}
& Z_{0}=(0,0,0,0,0,0,1,0,0,1,0,0,0), \\
& Z_{1}=(0,1,0,1,0,0,1,0,0,1,0,0,0), \\
& Z_{2}=(1,1,1,1,0,0,1,0,0,1,0,0,0), \text { and } \\
& Z_{3}=Z_{2} .
\end{aligned}
$$

As a further example, we consider a coalition composed of three firms: $S=\{6,10,12\}$ in the same corporate network. At the first step, $S$ controls Company 5 , then $S$ controls Firm 2, then Firm 3, and finally Firm 1.

As a result, we have:

$$
\begin{aligned}
& Z_{0}=(0,0,0,0,0,1,0,0,0,1,0,1,0), \\
& Z_{1}=(0,0,0,0,1,1,0,0,0,1,0,1,0), \\
& Z_{2}=(0,1,0,0,1,1,0,0,0,1,0,1,0), \text { and } \\
& Z_{3}=(0,1,1,0,1,1,0,0,0,1,0,1,0), \text { and } \\
& Z_{4}=Z_{5}=(1,1,1,0,1,1,0,0,0,1,0,1,0) .
\end{aligned}
$$

Thus, we have a situation where coalition $\{6,10,12\}$ is winning if we take as a target any combination of Firms 1, 2, 3, and 5 and losing in the case of Firm 4 as a target. 
The Denti and Prati algorithm has exponential computational complexity; thus, the problem with computation can arise if the number of firms is large. This model was then extended in (Denti and Prati, 2004) in order to suitably classify the winning coalitions and calculate all of the coalitions of all relevance. In this paper, we consider only the model from (Denti and Prati, 2001). For a detailed description of the Denti and Prati algorithm, see (Denti and Prati, 2001). Of course, in order to apply the Denti and Prati model (or other game-theoretical approaches mentioned in this paper), direct control relations must be retrieved from the data.

Denti and Prati did not consider power indices in their approach; however, having the set of all winning coalitions (or all minimal winning coalitions) is sufficient to determine a game. Thus, power indices can be applied to measure the control/power of firms in a corporate shareholding structure.

\section{4. "CONTROL SHARING SIMULATION" PROGRAM}

The lack of appropriate software greatly reduces the practical applications of the approaches to the modeling and calculating of indirect control proposed in the literature. Thus, Kołodziej (2011) proposed the "Control Sharing Simulation" program. "Control Sharing Simulation" is a computer program where the main task is to calculate and illustrate the level of control that firms exercise over other companies in either acyclic or cyclic corporate networks. This knowledge can be useful for competing companies or for predicting events that may arise in financial markets, for example. In particular, the "Control Sharing Simulation" program allows us to quickly and transparently create graphs, read and save graphs to files, and run the so-called "graphical algorithm", which clearly illustrates the degree of control of a preset coalition of firms on the rest of the companies. In Figure 5, the graphical interface of this program is presented.

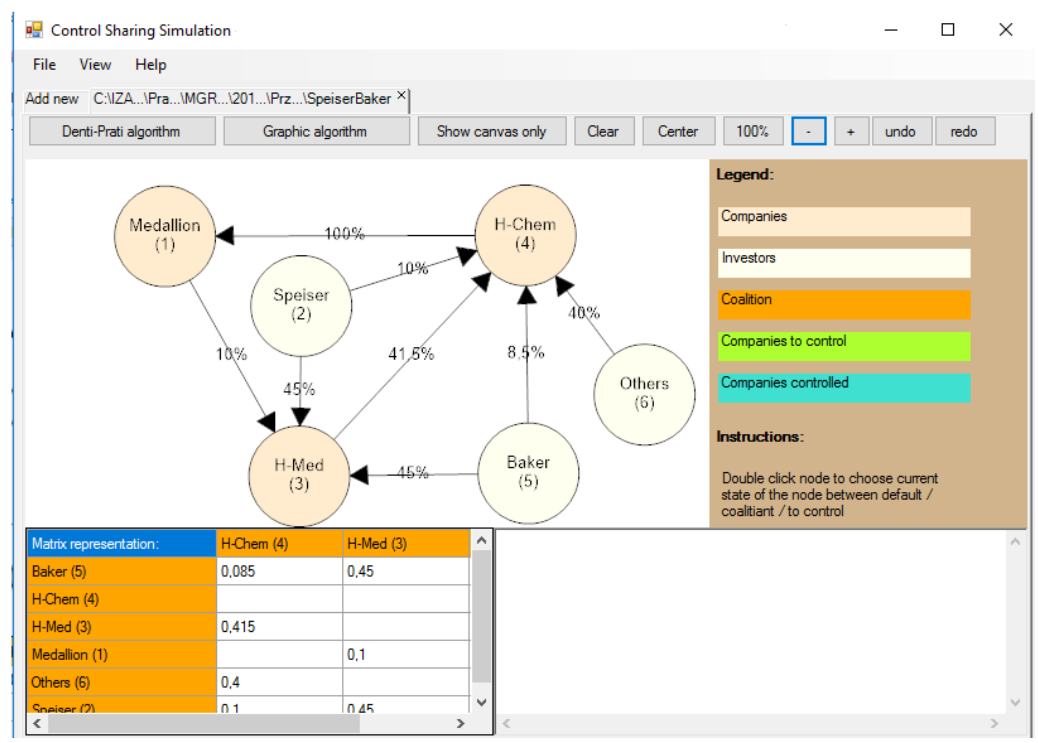

Fig. 5. Graphical user interface of "Control Sharing Simulation" program 
In the computer program, a user can change the status of a firm to three different types with a double-click on a node:

- "Default". The choice of this type indicates that a user is not interested in which firms can gain control over this company or which firms can be controlled by this firm.

- "Target company". The choice of this type indicates that a user is interested in which firms can exert control over this company.

- "Coalition". The choice of this type indicates that a user is interested in which companies can be controlled by this firm.

In order to run the Denti and Prati algorithm (or graphical algorithm), the user has to select at least one company for which he/she is interested in knowing which coalitions of firms are able to exert control over it. After running the algorithm, detailed calculations appear on the screen; so, it is possible to trace the steps of the Denti and Prati algorithm. The program not only enables us to perform the algorithm of Denti and Prati (i.e., finding all winning coalitions in a certain company), but it is also able to find the set of all minimal winning coalitions (a considerable improvement to the algorithm). We would like to underline that the most-complicated problem in implementing the application was simply creating an effective method for finding the set of all minimal winning coalitions. The Rosen algorithm was applied for this purpose [see, for example, (Rosen, 1991, pp. 284-286)]. The Rosen algorithm systematically generates all combinations of $\mathrm{n}$ firms from least- to most-numerous. Then, each newly formed coalition is immediately checked regarding whether it is a superset of the previously generated winning coalition or not. If not, then the Denti and Prati method is applied in order to check if this coalition is winning or losing. Because successively comparing coalitions (sets of companies) would be burdensome for application speed, each coalition of firms is numbered. Since this number can be very large $\left(2^{n}\right.$, where $n$ is equal to the number of firms), the BigInteger type was applied. This type is used to store very large numbers. In this effective way, a set of all minimal winning coalitions is created.

In particular, if we choose a target company in the Denti-Prati option of the application but do not indicate any coalition, then we obtain the following information as the results: the matrix that represents the considered corporate network, number and set of all minimal winning coalitions, number of winning coalitions, and number of all coalitions. In the case we also indicate a coalition of firms in order to check whether this coalition can exert control over a chosen target company, more-detailed calculations of the Denti-Prati algorithm can be obtained. Specifically, we receive the values of vector $\mathrm{Z}$ in all steps of the algorithm as well as the information about whether the chosen coalition is winning or losing.

To sum up: for a given corporate network, the program allows us to perform a simulation that is able to:

- create a direct graph as well as the corresponding matrix representation of direct ownership,

- find all minimal winning coalitions that control a preset coalition of firms,

- find all winning coalitions that control a preset coalition of firms, 
- check whether or not a certain coalition of firms is able to control a preset coalition of firms,

- illustrate via graphics the degree of control of the chosen coalition of firms on the rest of companies.

In the application "Control Sharing Information", a number of helpful tools have been implemented to facilitate the creation of graphs and calculate indirect control. To run the program requires at least Windows XP, Windows Vista, or Windows 7 (or higher) installed together with the .NET framework (version 4.0 at a minimum) or Linux operating system and an application compiled in Mono runtime (version 2.8 at a minimum). The following technologies and tools have been used to implement the project: Visual Studio 2010, programming language C\#, NET framework version 4.0, Library to display graphs - Piccolo20, XML.

\section{SOME SIMULATIONS}

In this section, we perform some simulations that take into account the Denti and Prati algorithm as well as the three shareholding structures presented in Section 2. First, we recall the simulations carried out in (Kołodziej and Stach, 2016) for two real-world examples. Then, we present the results of a simulation performed for the theoretical case. All of the simulations are performed thanks to the computer program "Control Sharing Simulation" presented in Section 4. Furthermore, in each example of shareholding networks, we compute some power indices in order to measure the power control and (as a consequence) better emphasize the role of the agents. Specifically, we consider three power indices that are based on the concept of the critical player: the Shapley and Shubik (1954), normalized Banzhaf (1965), and Johnston (1978) indices; and another one - the Holler (1982) index, which is based on the minimal winning coalitions. The first three mentioned indices give more power to a player who is critical in more winning coalitions. Of course, these indices also take into account other aspects than criticality for the coalitions [see, for example, (Bertini et al., 2013)]; but here, we do not enter in these particularities. The Holler index gives more power to players belonging to more minimal winning coalitions. In this section, we use the following abbreviations for our convenience: $\sigma$ stands for the Shapley and Shubik index; $\beta$ stands for the normalized Banzhaf index; $\gamma$ stands for the Johnston index; and stands for the Holler index.

Let us regard the Porsche-Volkswagen case with a majority quota of $q=80 \%$. Figure 2 and Table 1 present the direct ownership relationships in the Porsche and Volkswagen corporate shareholding structure. In this case, we can be interested in which alliances of firms can control Companies 4, 5, and 6, for example. After running the program "Control Sharing Simulation", we obtain that no investor alone is able to control these companies. In this case, there are two minimal winning coalitions of investors $(\{1,2,3\}$ and $\{1,3,7\})$ that can control these companies, and three winning coalitions $(\{1,2,3\},\{1,3,7\}$, and $\{1,2,3,7\})$. Porsche Family (1) and Lower Saxony (3) jointly do not manage to control Companies 4,5 , and 6 . It is necessary to cooperate with Qatar (2) or Others (7). In practice, as Others (7) represents the set of small undefined shareholders, an alliance with Qatar (2) seems to be a more-reliable coalition. 
Table 1. The simplified matrix representation of the Porsche-Volkswagen case

\begin{tabular}{|l|c|c|c|}
\cline { 2 - 4 } \multicolumn{1}{c|}{} & Porsche AG (6) & Porsche SE (4) & Volkswagen AG (5) \\
\hline Lower Saxony (3) & & & 0.200 \\
Others (7) & & 0.900 & 0.123 \\
Porsche Family (1) & & & 0.507 \\
Porsche SE (4) & & 0.100 & 0.170 \\
Qatar (2) & 1 & & \\
Volkswagen AG (5) & 1 & & \\
\hline
\end{tabular}

Table 2 gives the distribution of power among Firms 1, 2, 3, and 7 in the Porsche-Volkswagen case, with Companies 4, 5, and 6 as a target coalition. We see that, in Table 2, the power indices assign different power to the investors; but in all indices, Firms 1 and 3 have equal power (both greater than the power assigned to Firms 2 and 7). This is because both Firms 1 and 3 belong to all winning coalitions, and they are critical members in these coalitions, whereas Firms 2 and 7 belong to only one minimal winning coalition each. We see how powerful Lower Saxony (3) is in controlling companies 4, 5, 6. With only $20 \%$ of the voting rights in Volkswagen AG (5), Lower Saxony has equal power to Porsche Family (1), which alone controls Porsche SE (4) and, via this company, indirectly has $50.7 \%$ of the voting rights in Volkswagen AG (5).

Table 2. Power of investors in Companies 4, 5, and 6 in Porsche-Volkswagen case

\begin{tabular}{|c|c|c|c|c|}
\hline \multirow{2}{*}{ Power index } & \multicolumn{4}{|c|}{ Firm } \\
\cline { 2 - 5 } & $\mathbf{1}$ & $\mathbf{2}$ & $\mathbf{3}$ & $\mathbf{7}$ \\
\hline$\sigma$ & 0.4166 & 0.0833 & 0.4166 & 0.0833 \\
$\beta$ & 0.3750 & 0.1250 & 0.3750 & 0.1250 \\
$\gamma$ & 0.3889 & 0.1111 & 0.3889 & 0.1111 \\
$h$ & 0.3333 & 0.1667 & 0.3333 & 0.1667 \\
\hline
\end{tabular}

If we only take Company 6 (Porsche AG) into consideration as the target company, and we allow the coalitions of investors and companies, we obtain that there are 63 non-empty coalitions. Five of them are minimal winning coalitions $(\{5\},\{1,2,3\}$, $\{1,3,7\},\{2,3,4\},\{3,4,7\})$, and forty-one are winning. The rest of the coalitions $(63-41=22)$ are losing. Of course, not knowing the above results, we can ask if a particular coalition is able to exert power over a preset firm or group of firms. For example, let us consider Company 6 as a target company, and coalition $\{1,2,7\}$ is losing. If we perform the graphical algorithm of the "Control Sharing Simulation" program for the same coalition $(\{1,2,7\})$, the result is confirmed (see Fig. 6). Figure 6 illustrates that jointly, Firms 1 and 2 fully control Company 4 (Porsche SE), but coalition $\{1,2,7\}$, having $80 \%$ of the voting rights in Company 5 (Volkswagen AG), is not able to exert power and push for their decision in Company 5. Specifically, according to some laws, it is necessary to have more than $80 \%$ of the voting rights to make important decisions in Volkswagen AG. 


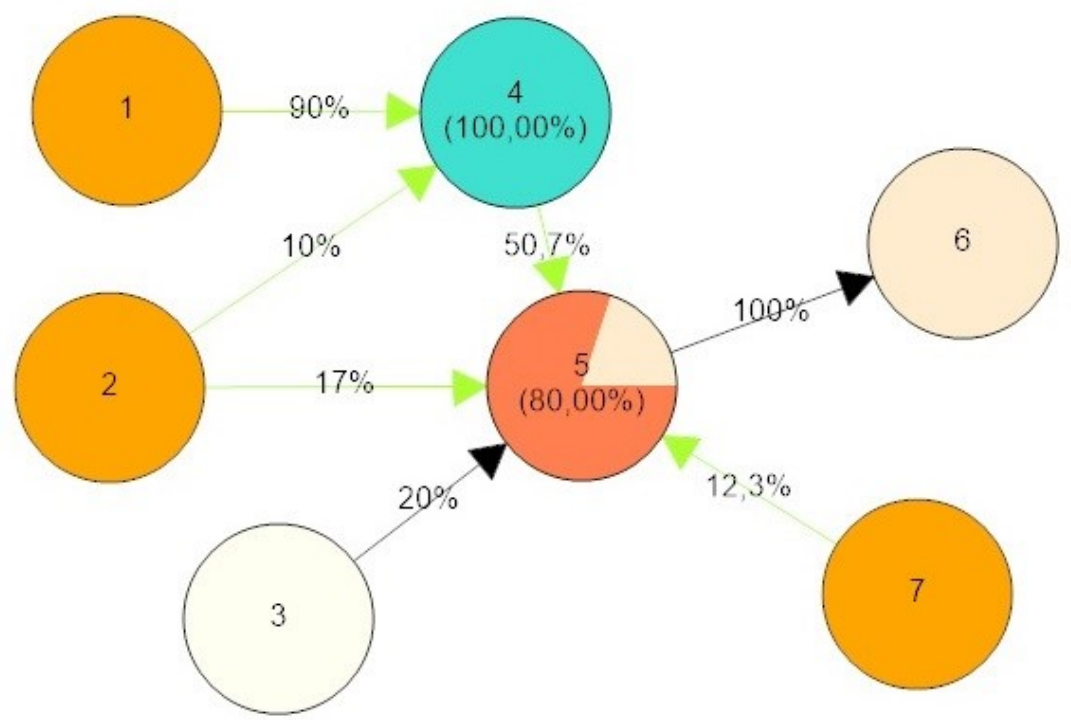

Fig. 6. Porsche-Volkswagen case: levels of control (in percentages) of Firms 1, 2, 7 in Companies 4, 5, 6

Remaining with Firm 6, let us look at power distribution. Firm 5 alone manages to control Company 6, so this means that all coalitions that include Firm 5 are winning coalitions. Therefore, it is not surprising that Firm 5 is the most-powerful according the Shapley-Shubik, Banzhaf, and Johnston indices (see Tab. 3). However, the most-powerful according to the Holler index is Firm 3, which belongs to as many as four minimal winning coalitions, whereas Firm 5 is the least powerful, as it belongs to only one minimal winning coalition (see Tab. 3). Then, all of the indices considered here give the same power to Firms 1, 2, 4, and 7. This is not surprising, as these firms are critical for the same number of winning coalitions (that is three), and they also belong to the same number of minimal winning coalitions. Specifically, each of these firms belongs to two minimal winning coalitions.

Table 3. Power of investors in Company 6 in Porsche-Volkswagen case

\begin{tabular}{|c|c|c|c|c|c|c|}
\hline \multirow{2}{*}{ Power index } & \multicolumn{7}{|c|}{ Firm } \\
\cline { 2 - 7 } & $\mathbf{1}$ & $\mathbf{2}$ & $\mathbf{3}$ & $\mathbf{4}$ & $\mathbf{5}$ & $\mathbf{7}$ \\
\hline$\sigma$ & 0.050 & 0.050 & 0.167 & 0.050 & 0.633 & 0.050 \\
$\beta$ & 0.068 & 0.068 & 0.205 & 0.068 & 0.523 & 0.068 \\
$\gamma$ & 0,036 & 0,036 & 0.135 & 0,036 & 0.719 & 0.036 \\
$h$ & 0.154 & 0.154 & 0.308 & 0.154 & 0.077 & 0.154 \\
\hline
\end{tabular}

Firm 5 is directly controlled by two minimal winning coalitions $(\{2,3,4\}$ and $\{3,4,7\})$ and also indirectly by two minimal winning coalitions $(\{1,2,3\}$ and $\{1,3,7\})$. By the way mentioned here, minimal winning coalitions are the same coalitions that are also minimal winning coalitions in games with Company 6 as the target 
company. But here, we see that Firm 3 is the most-powerful with accordance of all of the power indices, and all other players have differences in numbers but the same level of power (see Tab. 4).

Table 4. Power of investors in Company 5 in Porsche-Volkswagen case

\begin{tabular}{|c|c|c|c|c|c|}
\hline \multirow{2}{*}{ Power index } & \multicolumn{5}{|c|}{ Firm } \\
\cline { 2 - 6 } & $\mathbf{1}$ & $\mathbf{2}$ & $\mathbf{3}$ & $\mathbf{4}$ & $\mathbf{7}$ \\
\hline$\sigma$ & 0.117 & 0.117 & 0.533 & 0.117 & 0.117 \\
$\beta$ & 0.143 & 0.143 & 0.429 & 0.143 & 0.143 \\
$\gamma$ & 0.130 & 0.130 & 0.482 & 0.130 & 0.130 \\
$h$ & 0.167 & 0.167 & 0.333 & 0.167 & 0.167 \\
\hline
\end{tabular}

Of course, the "Control Sharing Simulation" program lets us change the majority quota and perform other simulations. If we change the majority quota to $q=50 \%$ in the Porsche-Volkswagen case, we create a situation where Porsche Family (1) controls all companies $(4,5,6)$; thus, there is only one minimal winning coalition $(\{1\})$ and eight winning coalitions. By the way, all of these winning coalitions contain Firm 1 (Porsche Family), and all power indices give a maximum power equal to 1 to Firm 1.

In the Baker and Speiser case (see Fig. 3 or Tab. 5), the corporate shareholding structure has a loop: Company 1 (Medallion) is fully controlled by Company 4 (HealthChem), then Company 3 (HealthMed) has $41.5 \%$ of the voting rights in Company 4, and again Company 1 (Medallion) possesses $10 \%$ of the voting rights in Company 3. The presence of a loop in a corporate network creates some problems in certain approaches, but not in Denti and Prati. Running the program, we also obtain that no investor in this case is able control all Companies $(4,5,6)$ itself. In total, there are five losing coalitions: three singleton coalitions $(\{2\},\{5\},\{6\})$ and two 2-person coalitions $(\{2,6,\{5,6\})$ - all with Firm 6 . Next, there are two winning coalitions $(\{2,5\}$ and $\{2,5,6\})$ but only one minimal winning coalition. Specifically, Players 2 (Speiser) and 5 (Baker) jointly control HealthMed (3), HealthChem (4), and Medallion (1).

Table 5. Simplified matrix representation of Speiser and Baker case

\begin{tabular}{|l|c|c|c|}
\cline { 2 - 4 } \multicolumn{1}{c|}{} & HealthChem (4) & HealthMed (3) & Medallion (1) \\
\hline Baker (5) & 0.085 & 0.450 & \multirow{2}{*}{ HealthChem (4) } \\
HealthMed (3) & 0.415 & & \\
Medallion (1) & & 0.100 & \\
Others (6) & 0.400 & & \\
Speiser (2) & 0.100 & 0.450 & \\
\hline
\end{tabular}

Thanks to the "graphic algorithm", we can see in Figure 7 the degrees of control (in percentages) of Firms 2 (Speiser) and 5 (Baker) in Companies 1, 3, and 4. Speiser (2) and Baker (5) directly manage to control only HealthMed (3), together holding $90 \%$ of the voting rights in this company. However, thanks to indirect control, they have 
$60 \%$ of the voting rights in HealthChem (4) and fully control Medallion (1) and HealthMed (3). Also, all of the power indices considered here confirm that Firms 2 and 5 are the most-powerful and hold the same power: 0.5 .

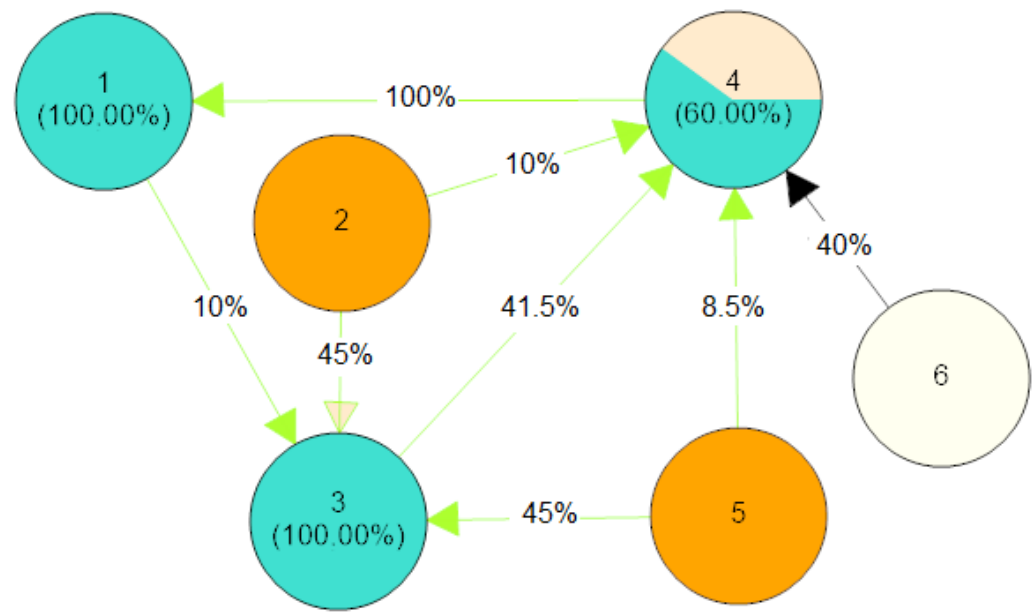

Fig. 7. Baker and Speiser case: levels of control (in percentages) of Firms 2 and 5 in Companies 1, 3, and 4

If we only take Company 3 into consideration in the Speiser and Baker case, we obtain that there are five minimal winning coalitions that control this company: $\{1,2\},\{1,5\}$, and $\{2,5\}$ (which control directly) and $\{2,4\}$ and $\{4,5\}$ (which control indirectly). In Table 6 , we have power distribution according to the power indices considered here. Firm 6 is not critical for any winning coalition and does not belong to any minimal winning coalition, so it is a dummy player; in accordance to all of the power indices considered here, its power is equal to zero. Also, the most-powerful here are Firms 2 and 5, as they obtain the same power. Firm 4 and Firm 1 (which is directly controlling by Firm 4) have the same power, but it is less than in Firms 2 and 5.

Table 6. Power of investors in Company 3 in Speiser and Baker case

\begin{tabular}{|c|c|c|c|c|c|}
\hline \multirow{2}{*}{ Power index } & \multicolumn{5}{|c|}{ Firm } \\
\cline { 2 - 6 } & $\mathbf{1}$ & $\mathbf{2}$ & $\mathbf{4}$ & $\mathbf{5}$ & $\mathbf{6}$ \\
\hline$\sigma$ & 0.167 & 0.333 & 0.167 & 0.333 & 0 \\
$\beta$ & 0.167 & 0.333 & 0.167 & 0.333 & 0 \\
$\gamma$ & 0.143 & 0.357 & 0.143 & 0.357 & 0 \\
$h$ & 0.200 & 0.300 & 0.200 & 0.300 & 0 \\
\hline
\end{tabular}

Regarding Company 4 as a target company, we also have five minimal winning coalitions; two of which control it directly $(\{2,3\}$ and $\{3,6\})$ and three that control it indirectly $(\{1,2\},\{2,5\}$, and $\{1,5,6\})$. Let us consider the power distribution in Company 4 as a target firm (see Tab. 7). Even though Firm 2 has only $10 \%$ of the voting rights in Company 4 (much less than Company 3, which has $41.5 \%$ of the 
voting rights in Company 4), it is the most-powerful firm in accordance with all of the power indices considered here (see Tab. 7). In Table 7, we see that all indices give the same power to Firms 1 and 5 . This is because these firms are critical in three winning coalitions. Specifically, Firm 1 is critical in $\{1,2\},\{1,2,6\}$, and $\{1,5,6\}$, and Firm 5 is critical in the following winning coalitions: $\{2,5\},\{2,5,6\}$, and $\{1,5,6\}$. The Holler index assigns the same power even to four firms: $1,3,5$, and 6 . This is because each of these firms belongs to two minimal winning coalitions. Then, all indices expect the Johnston index give the same power to Firms 3 and 6 . Firms 3 and 6 are critical in the same number of winning coalitions. More precisely, Firm 3 is critical in $\{2,3\},\{3,6\},\{2,3,6\},\{1,3,6\}$, and $\{3,5,6\}$, and Firm 6 is critical in $\{3,6\}$, $\{1,3,6\},\{1,5,6\},\{3,5,6\}$, and $\{1,3,5,6\}$. Thus, the Shapley-Shubik and Banzhaf indices assign the same power to Firms 3 and 6 . We see that the coalitions in which Firm 6 is critical are generally more numerous than the coalitions in which Firm 3 is critical. Thus, the Johnston index, which is reciprocally proportional to the cardinality of the winning coalitions in which a player is critical, gives more power to Firm 3.

Table 7. Power of investors in Company 4 in Speiser and Baker case

\begin{tabular}{|c|c|c|c|c|c|}
\hline \multirow{2}{*}{ Power index } & \multicolumn{5}{|c|}{ Firm } \\
\cline { 2 - 6 } & $\mathbf{1}$ & $\mathbf{2}$ & $\mathbf{3}$ & $\mathbf{5}$ & $\mathbf{6}$ \\
\hline$\sigma$ & 0.117 & 0.3667 & 0.200 & 0.117 & 0.200 \\
$\beta$ & 0.120 & 0.360 & 0.200 & 0.120 & 0.200 \\
$\gamma$ & 0.089 & 0.433 & 0.200 & 0.089 & 0.189 \\
$h$ & 0.182 & 0.273 & 0.182 & 0.182 & 0.182 \\
\hline
\end{tabular}

Table 8 and Figure 4 represent an example of a theoretical cyclic shareholding network composed of 13 firms and with the presence of cross-shareholding. Also in this example, no investor is able control all companies $(1,2,3,4,5)$ itself.

Table 8. Simplified matrix representation of theoretical example

\begin{tabular}{|c|c|c|c|c|c|}
\hline Firm & $\mathbf{1}$ & $\mathbf{2}$ & $\mathbf{3}$ & $\mathbf{4}$ & $\mathbf{5}$ \\
\hline 1 & & & & 0.03 & \\
10 & & 0.35 & & & \\
11 & 0.05 & & & 0.02 & \\
12 & & & & & 0.45 \\
13 & 0.05 & & & & \\
2 & 0.35 & & 0.30 & & \\
3 & 0.20 & & & & 0.10 \\
4 & 0.30 & 0.05 & & & \\
5 & & 0.25 & & & \\
6 & & 0.05 & 0.30 & & 0.15 \\
7 & & 0.30 & 0.40 & 0.90 & 0.30 \\
8 & & & & 0.05 & \\
9 & 0.05 & & & & \\
\hline
\end{tabular}


Let us consider Investors 6 and 7. Investor 6 alone does not have sufficient voting rights to control any firm. Investor 7 , owning $90 \%$ of the voting rights in Company 4, controls it directly. Investor 7 with Company 4 holds only a $35 \%$ stake in Company 2, so they are not able to control it. If Investors 6 and 7 join forces (i.e., they form a coalition), then they will have $45 \%$ of the voting rights in total in Company 5 (still not sufficient to control Company 5); however, they will be able to exert control over Company 3 (having, in total, $70 \%$ of the voting rights in it). Company 3 has $10 \%$ of the voting rights in Company 5; thus, a coalition of Investors 6 and 7 will also be able to control Company 5 indirectly (through Company 3). Coalition $\{6,7\}$, controlling Company 5, also controls Company 2, and via Company 2, totally (in 100\%) Company 3. Now, coalition $\{6,7\}$ controlling Companies 2, 3, and 4, will also manage to control Company 1. As Company 1 holds a $3 \%$ stake in Company 4, coalition $\{6,7\}$ strengthens its position of up to a $93 \%$ stake in Company 4 . Of course, Company 1 is directly controlled by minimal winning coalitions $\{2,3\}$ and $\{2,4\}$. Figure 8 shows the degrees of control (in percentages) of Investors 6 and 7 in all companies. This result was obtained quickly by running the graphical algorithm of the computer program.

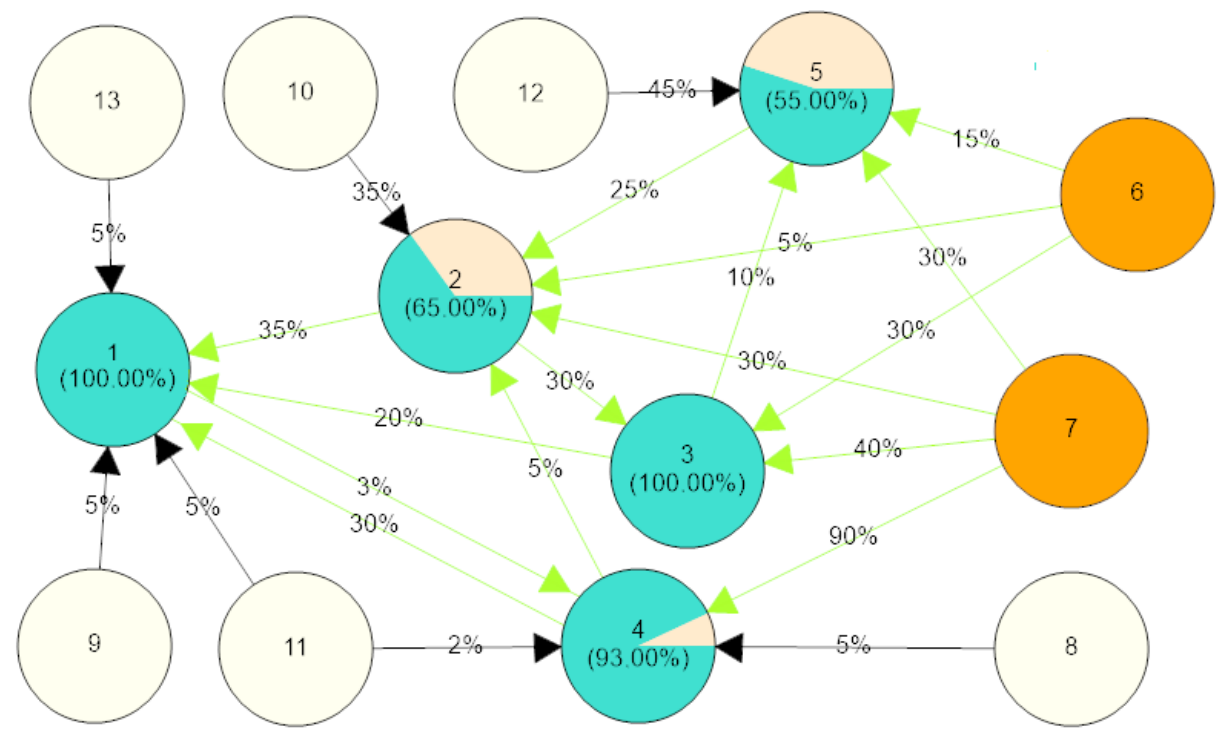

Fig. 8. Theoretical case: degrees of control (in percentages) of Investors 6 and 7 in companies

In Table 9, we have the results of the Denti-Prati algorithm for different target companies. Let us consider Company 1 as a target company. Running the computer program "Control Sharing Simulation," we immediately obtain that, in the considered example, there are 19 minimal winning coalitions within 3368 winning coalitions that can directly or indirectly control Company 1 (see Tab. 9). The total number of non-empty coalitions composed of Firms 2, 3, 4, ., 13 is equal to 4095. Note that Company 3 is a member in as many as nine of the coalitions above. No other 
firm is a member of so many minimal winning coalitions. Hence, we can imply that Company 3 is the most-powerful firm in the whole shareholding network with the target Company 1. And this inference is confirmed by the Holler index, which is based on the minimal winning coalitions (see Tab. 10).

Table 9. Results of simulations for different target companies

\begin{tabular}{|c|c|c|c|c|c|}
\hline & \multicolumn{5}{|c|}{ Company } \\
\hline & 1 & 2 & 3 & 4 & 5 \\
\hline $\begin{array}{c}\text { Number of } \\
\text { minimal } \\
\text { winning } \\
\text { coalitions }\end{array}$ & 19 & 7 & 8 & 1 & 4 \\
\hline $\begin{array}{c}\text { Minimal } \\
\text { winning } \\
\text { coalitions }\end{array}$ & $\begin{array}{c}\{10,7\},\{12,7\}, \\
\{2,3\},\{2,4\}, \\
\{2,6\},\{2,7\},\{5,7\}, \\
\{6,7\},\{10,12,3\}, \\
\{10,12,6\},\{10,3,5\}, \\
\{10,4,5\},\{10,5,6\}, \\
\{11,3,4\},\{11,3,7\}, \\
\{13,3,4\},\{13,3,7\}, \\
\{3,4,9\},\{3,7,9\}\end{array}$ & $\begin{array}{c}\{10,5\}, \\
\{10,7\}, \\
\{12,7\}, \\
\{5,7\},\{6,7\}, \\
\{10,12,3\}, \\
\{10,12,6\}\end{array}$ & $\begin{array}{c}\{10,7\}, \\
\{12,7\}, \\
\{2,6\},\{2,7\}, \\
\{5,7\},\{6,7\}, \\
\{10,12,6\}, \\
\{10,5,6\}\end{array}$ & $\{7\}$ & $\begin{array}{c}\{12,3\}, \\
\{12,6\}, \\
\{12,7\},\{6,7\}\end{array}$ \\
\hline $\begin{array}{c}\text { Number } \\
\text { of winning } \\
\text { coalitions }\end{array}$ & 3368 & 2624 & 2688 & 2048 & 2304 \\
\hline
\end{tabular}

Table 10. Power of players in theoretical example with Company 1 as target firm

\begin{tabular}{|c|c|c|c|c|c|c|c|c|c|c|c|c|}
\hline \multirow{2}{*}{$\begin{array}{c}\text { Power } \\
\text { index }\end{array}$} & $\mathbf{2}$ & $\mathbf{3}$ & $\mathbf{4}$ & $\mathbf{5}$ & $\mathbf{6}$ & $\mathbf{7}$ & $\mathbf{8}$ & $\mathbf{9}$ & $\mathbf{1 0}$ & $\mathbf{1 1}$ & $\mathbf{1 2}$ & $\mathbf{1 3}$ \\
\cline { 2 - 11 } & 0.196 & 0.121 & 0.098 & 0.056 & 0.096 & 0.265 & 0 & 0.010 & 0.092 & 0.010 & 0.047 & 0.010 \\
$\beta$ & 0.182 & 0.139 & 0.115 & 0.052 & 0.088 & 0.252 & 0 & 0.009 & 0.105 & 0.009 & 0.040 & 0.009 \\
$\gamma$ & 0.204 & 0.121 & 0.092 & 0.035 & 0.079 & 0.346 & 0 & 0.005 & 0.082 & 0.005 & 0.027 & 0.005 \\
$h$ & 0.082 & 0.184 & 0.102 & 0.082 & 0.082 & 0.163 & 0 & 0.041 & 0.122 & 0.041 & 0.061 & 0.041 \\
\hline
\end{tabular}

Other power indices indicate Firm 7 as the most-powerful, and the Johnston index gives it the most power (see Tab. 10). This is because Firm 7 belongs to fewer minimal winning coalitions than Firm 3 (see Tab. 9), and Firm 7 is critical in more winning coalitions than Firm 3. If we only take investors into consideration, Firm 7 belongs to eight minimal winning coalitions and should have the greatest power/control within the investors. This fact is confirmed by all power indices (see Tab. 10). Meanwhile, Investor 8 (who does not belong to any of the minimal winning coalitions) is the least-powerful firm in the network. We can say that Firm 8 is a dummy player. At first glance, it could seem that Firm 8 is in the same situation as Firms 9 and 13, but this is not true. Investors 9 and 13 are important for some alliances. Specifically, Investor 9 
is critical for coalitions $\{3,4,9\}$ and $\{3,7,9\}$. This means that the above-mentioned coalitions without Firm 9 become losing coalitions. Investor 13 is also critical in two minimal winning coalitions: $\{3,4,13\}$ and $\{3,7,13\}$ (see Tab. 9). By the way, we can see that Firms 9 and 13 are in a symmetrical position; i.e., they can form minimal winning coalitions with the same firms: $\{3,4\}$ and $\{3,7\}$. Still regarding Firm 8, we can observe that Investor 8 is always a dummy player no matter which company is a target company (it does not belong to any minimal winning coalition and has power equal to 1 - see Table 9 and Tables 10-13). Looking at Table 10, we see that the Shapley and Shubik index gives the ranking of firms from most- to least-powerful: $7,2,3,4,6,10,5,12,9,11,13$, and 8 . The Johnston and Banzhaf indices give a bit different ranking. Specifically, the $\beta$ and $\gamma$ ndices assign more power to Firm 10 than to Firm 6, whereas in accordance to index $\sigma$, Firm 6 is more powerful than Firm 10. According to the Holler index, the most-powerful is Firm 3 (as mentioned above). The ranking given by this index is as follows: $3,7,10,4,2,5,6,12,9,11,13$, and 8 . Firms 9, 11, and 13 are at the same level of power in accordance to all of the indices considered here; other than Firm 8, they have the lowest power (see Tab. 10).

In regards to Company 4 as a target company, we have only one minimal winning coalition composed of Firm 7. This is not strange, as Firm 7 holds a 90\% stake in Company 4. So, it is a powerful dictator; as a consequence, it must belong to all winning coalitions. All power indices give this firm maximal power equal to 1 .

Regarding target Companies 2, 3, and 5, similar broad consideration can be made thanks to the results presented in Table 9 and Tables 11-13. Hereafter, we will only give some short notes.

Firm 7 is the most-powerful according to all indices if a target is Company 2 or, likewise, Company 3 (see Tabs. 11 and 12).

Table 11. Power of players in theoretical example with Company 2 as target firm

\begin{tabular}{|c|c|c|c|c|c|c|c|c|c|c|c|c|}
\hline \multirow{2}{*}{$\begin{array}{c}\text { Power } \\
\text { index }\end{array}$} & \multicolumn{10}{|c|}{ Firm } \\
\cline { 2 - 12 } & $\mathbf{1}$ & $\mathbf{3}$ & $\mathbf{4}$ & $\mathbf{5}$ & $\mathbf{6}$ & $\mathbf{7}$ & $\mathbf{8}$ & $\mathbf{9}$ & $\mathbf{1 0}$ & $\mathbf{1 1}$ & $\mathbf{1 2}$ & $\mathbf{1 3}$ \\
\hline$\sigma$ & 0 & 0.017 & 0 & 0.150 & 0.067 & 0.400 & 0 & 0 & 0.267 & 0 & 0.100 & 0 \\
$\beta$ & 0 & 0.021 & 0 & 0.146 & 0.063 & 0.396 & 0 & 0 & 0.271 & 0 & 0.104 & 0 \\
$\gamma$ & 0 & 0.011 & 0 & 0.117 & 0.044 & 0.500 & 0 & 0 & 0.256 & 0 & 0.072 & 0 \\
$h$ & 0 & 0.063 & 0 & 0.125 & 0.125 & 0.250 & 0 & 0 & 0.250 & 0 & 0.188 & 0 \\
\hline
\end{tabular}

Taking Company 3 into account as a target as well as the number of minimal winning coalitions to which a player belongs, we see that the power calculated using the Holler index assigns the same power to Firms 2, 5, and 12. Instead, taking into account the critically of the player, this means that the distribution is different when taking into account the $\sigma, \beta$, and $\gamma$ indices. Precisely, these firms $(2,5,12)$ have lower power, Firm 2 is less powerful than Firms 5 and 12 according to the $\sigma$ and $\beta$ indices, and according to $\gamma$, Firm 2 has more power than Firms 5 and 12 (see Tab. 12). 
Table 12. Power of players in theoretical example with Company 3 as target firm

\begin{tabular}{|c|c|c|c|c|c|c|c|c|c|c|c|c|}
\hline \multirow{2}{*}{$\begin{array}{c}\text { Power } \\
\text { index }\end{array}$} & \multicolumn{10}{|c|}{ Firm } \\
\cline { 2 - 12 } & $\mathbf{1}$ & $\mathbf{2}$ & $\mathbf{4}$ & $\mathbf{5}$ & $\mathbf{6}$ & $\mathbf{7}$ & $\mathbf{8}$ & $\mathbf{9}$ & $\mathbf{1 0}$ & $\mathbf{1 1}$ & $\mathbf{1 2}$ & $\mathbf{1 3}$ \\
\hline$\sigma$ & 0 & 0.013 & 0 & 0.050 & 0.250 & 0.433 & 0 & 0 & 0.083 & 0 & 0.050 & 0 \\
$\beta$ & 0 & 0.013 & 0 & 0.044 & 0.261 & 0.435 & 0 & 0 & 0.087 & 0 & 0.044 & 0 \\
$\gamma$ & 0 & 0.097 & 0 & 0.027 & 0.231 & 0.565 & 0 & 0 & 0.054 & 0 & 0.027 & 0 \\
$h$ & 0 & 0.111 & 0 & 0.111 & 0.222 & 0.278 & 0 & 0 & 0.167 & 0 & 0.111 & 0 \\
\hline
\end{tabular}

Regarding target Company 5, only Firms 3, 6, 7, and 12 have non-zero controlpower, and Firm 12 is the most-powerful according to all indices (see Tab. 13). Investor 12 with any firm from set $\{3,6,7\}$ is able to exert control over Company 5 .

Table 13. Power of players in theoretical example with Company 5 as target firm

\begin{tabular}{|c|c|c|c|c|c|c|c|c|c|c|c|c|}
\hline \multirow{2}{*}{$\begin{array}{c}\text { Power } \\
\text { index }\end{array}$} & \multicolumn{10}{|c|}{ Firm } \\
\cline { 2 - 12 } & $\mathbf{1}$ & $\mathbf{2}$ & $\mathbf{4}$ & $\mathbf{5}$ & $\mathbf{6}$ & $\mathbf{7}$ & $\mathbf{8}$ & $\mathbf{9}$ & $\mathbf{1 0}$ & $\mathbf{1 1}$ & $\mathbf{1 2}$ & $\mathbf{1 3}$ \\
\hline & 0 & 0 & 0.083 & 0 & 0.250 & 0.250 & 0 & 0 & 0 & 0 & 0.417 & 0 \\
$\gamma$ & 0 & 0 & 0.083 & 0 & 0.250 & 0.250 & 0 & 0 & 0 & 0 & 0.417 & 0 \\
$h$ & 0 & 0 & 0.071 & 0 & 0.214 & 0.214 & 0 & 0 & 0 & 0 & 0.500 & 0 \\
$h$ & 0 & 0 & 0.125 & 0 & 0.250 & 0.250 & 0 & 0 & 0 & 0 & 0.375 & 0 \\
\hline
\end{tabular}

\section{CONCLUSIONS}

In this paper, we dealt with the indirect power of corporations. This topic is important and complex in financial economics. It is not simple to model and then measure the indirect control in complex corporate networks with a large number of firms and with cross-shareholdings. The control/power over large part of companies in a shareholding network can be centralized in a small number of tightly-connected investors. Therefore, it is important to have some instruments to find the coalitions of firms that may exert control over a specific company or minimal coalitions (in size) that can control all companies in a closed shareholding structure. In the present paper, we presented three shareholding networks: one theoretical and two real-world examples of shareholding structures.

In the context of game theory, various studies have been made on analyzing, modeling and measuring indirect control in corporate networks. In Section 1, we mentioned some approaches; but in this paper, we only focused on the Denti and Prati model. In Section 5 (using the mentioned Denti and Prati approach), we performed some simulations thanks to the computer program "Control Sharing Simulation" (Kołodziej, 2011) for two real-world examples of corporate shareholding networks and one theoretical one mentioned above. The problem of applying the existing approaches to real-world corporate structures is due to the lack of adequate software. The "Control Sharing Simulation" program facilitates the application of the Denti and Prati algorithm. This program allows us to quickly create direct graphs representing 
a corporate network, read and save graphs to files, run the Denti and Prati algorithm, and finally graphically illustrate the degree of control exerted by a preset coalition of firms on the rest of the companies.

\section{ACKNOWLEDGMENTS}

This paper is based on the paper (Kolodziej and Stach, 2016) that was presented at the ICIL 2016 conference: 13th International Conference on Industrial Logistics, September 28 - October 1, Zakopane, Poland. The author would like to acknowledge Maksymilian Kołodziej for his continuous effort in improving the computer program "Control Sharing Simulation". Research is financed by the statutory funds No. 11/11.200.322 of the AGH University of Science and Technology.

\section{REFERENCES}

Bajuri, N.H., Chakravarty, S., Hashim, N.H., 2013. Analysis of Corporate Control: How Good is the Straffin Index? Matematika, 29(1b), pp. 129-140.

Bajuri, N.H., Chakravarty, S., Hashim, N.H., 2014. Analysis of corporate control: can the voting power index outshine shareholding size? Asian Academy of Management Journal of Accounting and Finance, 10(1), pp. 75-94.

Banzhaf, J.F., 1965. Weighted voting doesn't work. A mathematical analysis. Rutgers Law Review, 19, pp. 317-343.

Bertini, C., Freixas, J., Gambarelli, G., Stach, I., 2013. Comparing power indices. International Game Theory Review, 15(2), pp.1-19.

Bertini, C., Stach, I., 2015. On public values and power indices. Decision Making in Manufacturing and Services, 9(1), pp. 9-25.

Bertini, C., Mercik, J., Stach, I., 2016. Indirect control and power. Operations Research and Decisions, 26(2), pp. 7-30.

Braham, M., Steffen, F., 2003. A priori voting power in hierarchical organization. Presented at European Public Choice Society Conference, September 25-28. Aarhus, Denmark. Retrieved from https://www.researchgate.net/publication/A_PRIORI_VOTING_POWER_ IN_HIERARCHICAL_ORGANIZATIONS (accessed on 7 February 2017).

Crama, Y., Leruth, L., 2007. Control and voting power in corporate networks: concepts and computational aspects. European Journal of Operational Research, 178, pp. 879-893.

Crama, Y., Leruth, L., 2013. Power indices and the measurement of control in corporate structures. International Game Theory Review, 15(3), pp. 1-15.

Denti, E., Prati, N., 2001. An algorithm for winning coalitions in indirect control of corporations. Decisions in Economics and Finance, 24, pp. 153-158.

Denti, E., Prati, N., 2004. Relevance of winning coalitions in indirect control of corporations. Theory and Decision, 56, pp. 183-192.

Gambarelli, G., Owen, G., 1994. Indirect control of corporations. International Journal of Game Theory, 23, pp. 287-302.

Holler, M.J., 1982. Forming coalitions and measuring voting power. Political Studies, 30, pp. 262-271. 
$\mathrm{Hu}$, X., Shapley, L.S., 2003a. On authority distributions in organizations: equilibrium. Games and Economic Behavior, 45, pp. 132-152.

$\mathrm{Hu}$, X., Shapley, L.S., 2003b. On authority distributions in organizations: controls. Games and Economic Behavior, 45, pp. 153-170.

Johnston, R.J., 1978. On the measurement of power. Some reactions to Lawer. Environment and Planning A, 10, pp. 907-914.

Karos, D., Peters, H., 2015. Indirect control and power in mutual control structures. Games and Economic Behavior, 92, pp. 150-165.

Kołodziej, M., 2011. Indirect control of corporations: analysis of models and their computer implementation. Master thesis, supervisor: Izabella Stach, AGH University of Science and Technology, Faculty of Management, Krakow.

Kołodziej, M., Stach I., 2016. Control sharing analysis and simulation. In: Sawik, T. (ed.), Conference Proceedings: ICIL 2016: 13th International Conference on Industrial Logistics, 28 September - 1 October, Zakopane, Poland, pp. 101-108, AGH University of Science and Technology, Krakow.

Krause, S.M., Peixoto, T.P., Bornholdt, S., 2013. Spontaneous Centralization of Control in a Network of Company Ownerships, PLoS ONE, 8(12): e80303. Retrieved from http:// journals.plos.org/plosone/article?id=10.1371/journal.pone.0080303 (accessed on: 10 January 2016).

Mercik, J., Łobos, K., 2016. Index of implicit power as a measure of reciprocal ownership. Springer Lecture Notes in Computer Science, 9760, pp. 132-145.

Penrose, L.S., 1946. The elementary statistics of majority voting. Journal of the Royal Statistical Society, 109, pp. 53-57.

Penrose, L.S., 1952. On the objective study of crowd behaviour. H.K. Lewis Co., London.

Rosen, K.H., 1991. Discrete Mathematics and Its Applications, McGraw-Hill, New York.

Shapley, L.S., Shubik, M., 1954. A method for evaluating the distributions of power in a committee system. American Political Science Review, 48, pp. 787-792.

Stach, I., 2011. Shapley-Shubik index. In: Dowding, K. (ed.), Encyclopedia of Power, SAGE Publications, Los Angeles, pp. 603-606.

Stach, I., 2016. Power Measures and Public Goods. In: Nguyen, N.T., Kowalczyk, R., Mercik, J. (eds.), Transactions on Computational Collective Intelligence XXIII, Vol. 9760 of the series Lecture Notes in Computer Science, pp. 99-110.

Straffin, P.D., 1977. Homogeneity, independence, and power indices. Public Choice, 30, pp. $107-118$.

Straffin, P.D., 1988. The Shapley-Shubik and Banzhaf power indices as probabilities. In: Roth, A.E. (ed.), Shapley Value, Cambridge University Press, Cambridge.

Straffin, P.D., 1994. Power and stability in politics. In: Aumann, R.J., Hart, S. (eds.), Handbook Game Theory, Elsevier Science.

Turnovec, F., 1999. Privatization, ownership structure and transparency: how to measure the true involvement of the state. European Journal of Political Economy, 15, pp. 605-618.

Vitali, S., Glattfelder, J.B., Battiston, S., 2011. The network of global corporate control, PLoS ONE6, 10: e25995. Retrieved from http://dx.doi.org/10.1371/journal.pone. 0025995 (accessed on: 23 January 2017).

Van den Brink, R., Steffen, F., 2008. Positional power in hierarchies. In: Braham, M., Steffen, F. (eds.), Power, Freedom, and Voting, Springer, Berlin, Heidelberg, pp. 57-81. 